\title{
Local communities and health disaster management in the mining sector
}

\begin{tabular}{|c|c|}
\hline $\begin{array}{l}\text { Authors: } \\
\text { Freek Cronje }{ }^{1} \\
\text { Suzanne Reyn } \\
\text { David van Wyl }\end{array}$ & $e^{1} e^{1}$ \\
\hline \multicolumn{2}{|c|}{$\begin{array}{l}\text { Affiliations: } \\
{ }^{1} \text { Bench Marks Centre } \\
\text { for Corporate Social } \\
\text { Responsibility (CSR), North- } \\
\text { West University, South Africa }\end{array}$} \\
\hline \multicolumn{2}{|c|}{$\begin{array}{l}\text { Correspondence to: } \\
\text { Freek Cronje }\end{array}$} \\
\hline \multicolumn{2}{|c|}{$\begin{array}{l}\text { Email: } \\
\text { freek.cronje@nwu.ac.za }\end{array}$} \\
\hline \multicolumn{2}{|c|}{$\begin{array}{l}\text { Postal address: } \\
\text { North-West University, } \\
\text { Potchefstroom Campus } \\
\text { Internal Box 312, } \\
\text { Potchefstroom 2520 }\end{array}$} \\
\hline \multicolumn{2}{|c|}{$\begin{array}{l}\text { Dates: } \\
\text { Received: } 23 \text { Aug. } 2012 \\
\text { Accepted: } 11 \text { Jan. } 2013 \\
\text { Published: } 12 \text { Mar. } 2013\end{array}$} \\
\hline \multicolumn{2}{|c|}{$\begin{array}{l}\text { How to cite this article: } \\
\text { Cronjé, F., Reyneke, S. \& } \\
\text { Van Wyk, D., 2013, 'Local } \\
\text { communities and health } \\
\text { disaster management in } \\
\text { the mining sector', Jàmbá: } \\
\text { Journal of Disaster Risk } \\
\text { Studies 5(2), Art. \#78, } \\
12 \text { pages. http://dx.doi. } \\
\text { org/10.4102/jamba.v5i2.78 }\end{array}$} \\
\hline \multicolumn{2}{|c|}{$\begin{array}{l}\text { Note: } \\
\text { 1st Biennial Conference, } \\
\text { Southern African Society for } \\
\text { Disaster Reduction (SASDiR), } \\
09 \text { to } 11 \text { October 2012, } \\
\text { Potchefstroom, South Africa }\end{array}$} \\
\hline \multicolumn{2}{|c|}{$\begin{array}{l}\text { Copyright: } \\
\text { (C) 2013. The Authors. } \\
\text { Licensee: AOSIS } \\
\text { OpenJournals. This work } \\
\text { is licensed under the } \\
\text { Creative Commons } \\
\text { Attribution License. }\end{array}$} \\
\hline \multicolumn{2}{|l|}{ Read online: } \\
\hline 口ifing & $\begin{array}{l}\text { Scan this QR } \\
\text { code with your } \\
\text { smart phone or } \\
\text { mobile device } \\
\text { to read online. }\end{array}$ \\
\hline
\end{tabular}

Mining activities throughout the Southern African Development Community (SADC) have impacted on the health and safety of mining communities for many decades. Despite the economic contribution of mining to surrounding communities, a huge amount of social and environmental harm is associated with the industry. In this regard, mining companies have, on the one hand, contributed toward improved social development by providing jobs, paying taxes and earning foreign exchange. On the other hand, they have been linked publicly to poor labour conditions, corruption, pollution incidents, health and safety failings, as well as disrespect of human rights. The objectives of this study are to give an overview of social and natural factors relating to health disasters in selected communities in the mining environment. Regarding the findings, this paper focuses on the social and natural factors involved in the creation of health disasters. The social factors include poverty, unemployment, poor housing and infrastructure, prostitution and a high influx of unaccompanied migrant labour. Major health issues in this regard, which will be highlighted, are the extraordinary high incidence rate of HIV and STIs (sexually transmitted infections), addiction and mental illness. The environmental (natural) threats to health that will be discussed in the study are harmful particles in the air and water, excessive noise and overcrowded and unhygienic living conditions. In conclusion, the paper also finds that communities need to be 'fenced in' in terms of health disaster management instead of being excluded. Specific recommendations to mining companies to reduce health and safety disasters will be made to conclude the paper.

\section{Introduction}

Mining activities throughout the Southern African Development Community (SADC) have impacted on the health and safety of mining communities for many decades. Despite the economic contribution of mining to surrounding communities, a huge amount of social and environmental harm is associated with the industry. In this regard, Warhurst (1998:2) indicates that mining companies have, on the one hand, contributed towards improved social development by providing jobs, paying taxes, building an industrial base, enhancing efficiency, earning foreign exchange and transferring technology. On the other hand, they have been linked publicly to interference in sovereign affairs, deepening disparities in wealth, poor labour conditions, corruption, transfer pricing, pollution incidents, health and safety failings, as well as disrespect of human rights.

The Bench Marks Foundation (BMF) ${ }^{1}$, an international non-governmental organisation (NGO) based in Johannesburg, has done extensive research on communities adjacent to mining operations throughout the SADC region. The project - coined the SADC Mining Project - started in 2006 with different sources of international funding from the Netherlands, Switzerland and the United Kingdom, amongst others. Much of this research included worker- and mine-impacted and -affected community health and safety. Noting the great variations in health and safety standards throughout the region, the lack of consideration for community health and safety and the impact of community health and safety on mine operational health and safety, the BMF and the Bench Marks Centre for CSR are making a strong case for community involvement in the management of mine health and safety and disaster management.

The first study (2006) of the umbrella project started by investigating platinum mines around the Bojanala District followed by research on the other sectors in the industry in South Africa (coal, diamonds, gold and uranium). Consequently, the Kayelekera Uranium Mine in Malawi was scrutinised, and this was followed by a study of the Copperbelt in Zambia as well as research on the gold, copper and cobalt mining sectors in the Democratic Republic of Congo (DRC). The diamond industry in Botswana was researched in 2008 and 2009 and platinum mines in Zimbabwe also formed part of the research. Recently, on 14 August 2012, the well-known Policy Gap 6 Report was released (The Bench Marks Foundation 2012); this study was a follow-up on the first platinum

1.The Bench Marks Foundation is a partner in the newly formed research centre at the Potchefstroom Campus of the North-West University, named The Bench Marks Centre for CSR. 
study in 2006 and 2007, and became a standard referencing work after the Marikana tragedy, which broke out in August 2012. The SADC Mining Project is on-going and research is currently being planned for a study in Namibia. The mining operations being studied all represent potential disaster situations for communities living in close proximity to the mines, ranging from potential tailings failure, seismic events, explosions and road accidents, to respiratory problems, HIV, TB, and other health problems. In all cases, mine health and safety, as well as community health and safety, can be improved through increased community involvement in disaster management.

Broadly, this paper will draw on the research findings of the various studies, especially with regard to potential mine and community health disasters, and the management thereof, primarily through closer community involvement. In making the argument for closer community involvement, both traditional and modern mining communities will also be contrasted in terms of health impact. Specifically, due to the extensive ramifications of the overarching research project, the focus of this paper will be on a few selected communities in the Platinum Belt in South Africa.

As a side comment, it can be mentioned that Social Responsibility (SR) strongly comes to the fore when talking about health disasters: the responsibilities of the mining corporations as well as government on all levels are major agenda points in this regard. In support of the argument regarding corporations, Meeran (2003) believes that the lack of proper accountability by corporations has a damaging effect on society. As a result, the idea of Corporate Social Responsibility (CSR) is playing an increasingly important role in companies' policies in southern Africa, particularly in the case of the mining industry (Hamann \& Kapelus 2004:85). It can also be stated that significant legislative developments in terms of the well-being of citizens, especially in the work place (for example, the Constitution of South Africa 1996 \& the Mine Health and Safety Act 1996) and regarding disaster and risk management (Disaster Management Act 2002 \& National Disaster Management Framework 2005), have taken place since 1994; however, the implementation and monitoring of these legislative measures remain hugely problematic.

In conclusion, the problem statement of and rationale for this paper is that numerous potential health disasters are prevalent in communities adjacent to mining operations, specifically due to the impact of mining operations; 'social' and 'natural' health disasters are highly prominent in this regard. Furthermore, the argument is being made that greater community engagement (from the side of corporations as well as government) will enhance the effectiveness of health disaster management in these mining communities.

\section{Objectives}

The objectives of this paper are four-fold:

- To give an overview of social factors relating to health disasters in selected communities in the mining environment.
- To give an overview of natural factors relating to health disasters in selected communities in the mining environment.

- To contrast traditional and modern mining communities in the argument toward increased community involvement for health disaster management.

- To present recommendations in order to avoid or minimalise health disasters in the mining sector.

\section{Methodology}

The research under discussion (this paper) is to a large extent explorative as well as descriptive, with some explanatory attempts on certain issues. Two basic research procedures were used for the research presented in this paper as well as for the umbrella SADC project, namely:

- Historical procedure.

- Survey procedure.

The historical procedure (literature review) was used specifically for the historical, legislative, policy and industry overview of each country, for reviewing applicable programmes and policies for the industry in the region, as well as for the general analysis of the relationship between global, national and local forces and the mining industry per SADC country. More generally, the historical procedure was also used to conceptualise and contextualise all facets of the research, also for this paper. Books, scientific journal articles, popular articles, newspapers, reports, annual reports of mining companies, conference proceedings and databases as well as the Internet were used as sources for applying the historical procedure. In analysing the qualitative data, applicable literature was again used to recontextualise the findings.

To gather the empirical information, the survey procedure was used. When working with and in mining communities, a qualitative approach is the better choice for the subject matter in that it enables the respondents to expand on their points of view, without being limited by the questions. Data collection methods for this study included focus groups, researcher observations and interviews. As the elements of interviews with communities were not fixed beforehand, they were semi-structured and 'open' on the basis of a list of topics related to the interaction between mining companies, government and communities; and the environmental, cultural, socio-economic, political and health impact of mining on communities.

A degree of flexibility was allowed in order to assist the interviewers in probing deeper where it was felt that more relevant information could be obtained through further questioning. Questions and topics were not necessarily asked in the same order each time as this depended on the way the interview developed. This allowed the person being interviewed a degree of freedom to voice concerns and to participate in directing the flow of the conversation. These in-depth interviews assisted in clarifying what themes and topics are considered to be important, what the major 
concerns of individuals and communities are and the relationships between different strata within communities such as those who support mining development, those who oppose it, gender-related views, views of the youth, the aged, traditionalists and modernisers, and so on.

Focus groups (8-12 people) and interviewees were selected purposely to take account of gender, race, migrant or local status, age and specific interest groups in order to cover different variables regarding the health disaster focus. To enhance the scientific nature of the study, at least two researchers (interviewers), and a translator where necessary, facilitated each focus group and each personal interview. Different individuals in different areas were also used as key informants. Patton (2002:321) describes key informants as '... people who are particularly knowledgeable about the inquiry setting and articulate about their knowledge - people whose insights can prove particularly useful in helping an observer understand what is happening and why'. The researchers also attended meetings between communities and corporations, mining and other related conferences and NGO, CBO (community-based organisations) and FBO (faith-based organisations) workshops. Participatory observation was also used to gather information. Seeing that the authors and researchers were actively involved in the research process, and stayed in the respective areas for some time, several long-term observations were possible during the research period (including experiencing the effects of sulphur dioxide and polluted water, and socialising with local communities), giving an insight into the research setting. From these observations, additional data were documented by the research team through field notes.

The interviews with the respondents were translated, where necessary, and transcribed. The content of the data was then analysed by means of conceptual (thematic) analysis. According to Palmquist et al. (2005), the process of conceptual analysis comprises eight steps, namely:

- deciding on the level of analysis

- deciding on how many concepts to code for

- deciding whether to code for the existence or frequency of a concept

- deciding how to distinguish among the concepts

- developing rules for the coding of texts

- deciding what to do with irrelevant information

- coding texts

- analysing results.

A more theoretical (as opposed to a practical) approach - that is, the interpretation of written sources (literature control) was used as the basic point of departure for the analysis and interpretation of the results. Given the fact that the study approach was qualitative and inductive, 'synchronisation' of practice and theory took place while analysing the data where relevant literature, as already indicated earlier in the section, recontextualised and re-affirmed the findings.

According to Guba (in Krefting 1991), there are four important elements for increasing trustworthiness in qualitative research:
- Truth value: confidence in the truth of the findings and the context in which the study was undertaken.

- Applicability: the degree to which the findings can be applied to other contexts and settings or with other groups.

- Consistency: whether the findings would be consistent if the inquiry were replicated with the same subjects or in a similar context.

- Neutrality: the degree to which the findings are a function solely of the informants and conditions of the research and not of other biases.

The researchers tried their utmost to guide their research according to these elements during the study.

For the overarching SADC Mining Project, further investigation was also performed through the quantitative research paradigm by collecting data from questionnaires. These were compiled for use on mine management as well as on some community groups - depending on the literacy levels - throughout the SADC region.

The findings in this paper are however being reflected by mainly qualitative inquiry as well as observation, both objective and participatory. Five communities in the Platinum Belt in South Africa adjacent to mining operations with a similar socio-economic nature, namely black and poor with a high incidence of unemployment coupled with a poor infrastructure, were the locus of the study for this paper.

Consequently, health issues and potential related disasters in the mining sector will be highlighted.

\section{Health issues and related disasters in the mining industry}

There is considerable disagreement between mining communities and mining companies concerning the real health impacts of the industry, as well as the different responsibilities of key role-players. Literature reveals that mining activities can impact on the health of communities related to mine operations at various levels (Stephens \& Ahern 2001:30). Firstly, there are adverse health effects that result from environmental exposure to air, water, soil and noise pollution (Cronjé \& Chenga 2007). Secondly, and equally important for community health, there are nonenvironmental exposure and events such as mining disasters, pit closures, migration trends, poverty, unemployment, and poor infrastructure, which affect mining communities both indirectly and directly at different levels. With regard to the health impacts in the mining sector, it is important to differentiate between social factors and natural factors, and these will now be investigated in more detail.

\section{Social factors}

Mining communities throughout the SADC region, including South Africa, are characterised by poor social conditions, such as poverty, unemployment, poor housing 
and infrastructure, prostitution, and a high influx of unaccompanied migrant labour. Major health issues in this regard are the extraordinarily high incidence of HIV and STIs (sexually transmitted infections), unwanted pregnancies, malnutrition, alcohol addiction, and mental illness. Three of these issues - HIV, addiction and mental illness - are highlighted below.

\section{HIV}

One cannot talk about health in Africa and specifically South Africa without looking at the impact of HIV on the social, economic, and emotional level. When talking about HIV in a mining community, three factors come to the forefront, namely migrant labour, social structure, and infrastructure.

The epidemiology of HIV is closely linked to migrant labour. In the South African mining community context, migration both within borders and outside the South African borders has played a significant role in the initial spread of HIV. Brummer (2002:2) argues that the characteristics of the migration process have facilitated the rapid spread of HIV. The mode of transmission of HIV in southern Africa in the mining communities under this study is (mainly heterosexual) sexual intercourse. The communities were noticeably quiet when issues relating to homosexuality were raised, despite still having single sex male hostels housing thousands of men within their communities. Brummer adds that although HIV is a medical condition restricted to only a few modes of transmission, the political economy creates an environment that encourages transmission.

Migrant labour per se is not a risk factor for the transmission of HIV. Rather, it is risky sexual behaviour that increases the probability of transmission of HIV infection, and as the migrant labourer is vulnerable to becoming involved in risky sexual behaviour, this makes the South African mining migrant labourer an agent for transmission of the virus, both in the receiving and the sending communities. Caldwell et al. (in Brummer 2002) concur with this view by arguing that migration not only facilitates the rapid spread of the virus along the corridors of migration, but also causes behaviour (for example, non-selective multi-partner sexual activities) and situations (such as, large single sex hostels and the inability to bring partners to the mining environment) that facilitates transmission from one person to another. Focus on migrant workers should therefore be in terms of their vulnerability to HIV transmission, as opposed to their role as risk factors. For example, the focus on migrants as risk factors for the transmission of HIV led to Malawians being thrown out of South Africa in 1988, following false accusations that they were responsible for spreading HIV in that country. Webb (1997) suggests that vulnerability refers to the social, cultural, economic, and political environment of individuals, families, communities and society, and occurs in situations where people are limited in their ability to make free and informed decisions. He defines the risk situations as situations where, socially and geographically, the individual's capacity to respond effectively to health situations has been reduced.
In the South African context, the type of migration models and the environment in which migrant labourers live post-migration make them vulnerable to high-risk sexual behaviour. Bekker and Swart (2003:63-68) suggest that there are three models that often appear in the analysis of migration in South Africa, namely circulatory, oscillating and gravity migration. In terms of the labour migration that exists in the mining industry, and also specifically being found in this research on the Platinum Belt, the oscillating migration model is the most pertinent in terms of facilitating the spread of HIV. Oscillating migration refers to labour migration where an adult moves in search of a job, returns to the rural home after this job has been completed, and then repeats the cycle. The individual often undertakes this form of migration without the family. In terms of the environment that they find post-migration, the high-risk situations include overcrowded and poor single sex hostels, harsh working conditions, hostile and desperate surrounding communities with a strong dependency on the miners' incomes, and poor recreational facilities. The level of vulnerability is also influenced by whether the migrants are documented or undocumented and whether they are employed or unemployed. The situations encountered and the responses in terms of behaviour will vary from person to person.

What sets the mining migrant community apart from other migrant communities in terms of high risk for the transmission of HIV and dependence on prostitutes, is the exclusion of women from the mine's employment, and the single sex quarters.

In addition to the migrant labour issue, the poor social structure of mining communities is also conducive to the transmission of HIV. Factors that are going to be highlighted against this background are:

\section{- poverty}

- unemployment levels

- overcrowded housing

- family disorganisation

- culture.

The links between poverty and HIV are complex and not fully understood. Whiteside (2001:1-5) suggests that poverty has played - and continues to play - an important role in the spread of HIV. Colvin and Sharp (2001) concluded from data on the changing distribution of HIV that the poor are more vulnerable to being infected by the virus. From the research findings in this study, it is clear that the level of poverty in the communities is very high in terms of basic needs. Such basic needs include insufficient food, poor shelter, poor health care, and in some cases, no access to water. The issue of absolute poverty within these communities was echoed by various people and institutions that work closely with the communities, such as the executive mayor of the Bojanala platinum district, NGOs, medical personnel from the local clinics, teachers, church leaders, community leaders, and self-reports from the community members.

HIV itself has had a profound impact on the families of those suffering from the disease in terms of aggravating the level 
of poverty that the family experiences when caring for their relatives. Despite the government sanctioning a social grant of more or less R1000 (approximately \$125) per month to the person living with HIV, families still have to contribute financially towards the care of their relatives. The R1000 per month is not enough to cover the food, transport, treatment, and care for the person. In addition, the individual may also have a family that needs to be looked after. Consequently, this can result in resentment from those who have to contribute or envy from onlookers for the attention that the person is receiving. Suggestions have been made that focus should also be on those who are HIV-negative, in order to motivate them to remain so. Otherwise, understandably, some community members who are experiencing extreme poverty may find that the perceived comforts and benefits of being HIV-positive outweigh the real benefits of being HIVnegative.

The mining communities are characterised by high unemployment levels for the local community members and a large number of undocumented migrants seeking work. According to one of the general managers of a mining company on the Platinum Belt, it is estimated that the level of unemployment in the local communities is $40 \%$. Without a doubt, the most affected are women and the youth. The rapid change from rural societies to money-based societies creates social problems, especially for women, young adults and children. The displacement of people from rural communities where people have been able to fend for themselves for basic food has had a serious impact on issues such as food security, because the mining operations drastically change the nature of the communities and take away agrarian land from the communities. Communities are now characterised by high cash dependency with no informal activities relating to extra income earning projects such as cottage industries, backyard vegetable gardens, et cetera. In view of this, the levels of poverty are dependent on the employment status of the community members. Opportunities for women are very rare in mining communities. Consequently, some women take up prostitution as a way of earning income to feed themselves and the family.

Under the Mining Charter of South Africa and the Mineral and Petroleum Resources Development Act (MPRDA) of 2002, women must constitute $10 \%$ percent of the mining companies' labour force. High unemployment rates for women and the youth have serious implications with regard to the prevalence and spread of HIV, especially when these communities are in close proximity to more than 8000 men with money and little to spend it on except women and alcohol.

Unemployed women are more vulnerable to the transmission of HIV for several reasons. As wives, women are often dependent on their husbands for financial support and consequently find it difficult to enforce condom use or to refuse sex. Those who are not married have reported, through interviews and focus groups, being forced by their poor social circumstances into relationships in order to get financial support for their families. There are situations where women have offered their children to men in order to get continuous financial support for the family. Although this can be interpreted as a subtle form of prostitution and child abuse, overt prostitution is commonplace in these communities. Reports are that girls of school age are increasingly getting involved in prostitution. Several women reported that when women apply for work at the mines, they encounter 'sex for jobs' policies instituted by the recruitment officials. In some desperate situations, teenage girls have resorted to becoming pregnant in order to qualify for child support.

In general, the housing conditions in the study area are very poor. There is a serious shortage of adequate housing, with an estimated $80 \%$ of the population living in tin shacks (poorly-constructed corrugated sheds) as their permanent home. Initially, some of these tin shacks were set up by migrants, but in some areas the tin shacks accommodate both the local people and the migrants. The poor housing conditions have been blamed for the increase in the spread of disease because of overcrowding. In addition, these poor housing conditions also cause family disorganisation and early sexual experiences for the young, because in some instances, a shack can house three to four families, often only separated by curtains. The government is committed to a housing programme aiming at 'doing away' with shacks. The local authorities in the research setting reported that they are in a dilemma whereby they have the money to build houses, but the land belongs to the mine, and, as a consequence, they are unable to meet their targets.

Most of the issues discussed above can result in family disorganisation. Most examples of family disorganisation are the result of single parentage caused by teenage pregnancy and relationships with migrant contract workers who return home and leave the local women and children behind. Added to this is the increasing rate of child- and grandparentheaded families as a result of death from HIV. The problem for the survivors is that, by its nature, HIV can cause a slow, painful death that requires intensive care in terms of feeding, hygiene, and emotional support. Furthermore, it is shrouded by secrecy, making it difficult for the caregivers to seek support. In most cases it is the children who look after both parents until they die. These children have to pick up the pieces when their parents die. For migrant children especially, the problem is more severe because they are not entitled to child welfare benefits or support from the social support services as are their South African counterparts. The result of this is that either the children return to the sending communities, where they are effectively strangers, or they attempt to fend for themselves as street children, with all that that entails. These situations help to feed the HIV cycle.

The issue of 'African culture' and its perceived contribution to the high prevalence and incidence of HIV is a contentious subject amongst both scholars and laymen alike. It appears that there is no cultural reason why women cannot work in the mining sector. In fact, it would be good if women could work because it would help their husbands' income and 
reduce the rate of prostitution, which is a serious risk factor for the transmission of disease. It may be worth noting that the mining environment has generally been male-dominated; consequently, the facilities have not been accommodating in terms of dressing rooms for both genders. Because of this, the management view may be based on the company's lack of facilities rather than 'culture'.

Refusing to use condoms might be related to lack of knowledge of how to use the condom. Since the instructions are likely to be in a language they do not understand, a man may feel embarrassed about asking other men for help. Consequently, 'culture' is being used as an excuse.

At the onset, it is important to state that the African population is not homogenous; it is a heterogeneous population with a wide variety of different races, languages and cultures. This demographic picture is also reflected by the research setting in the Bojanala District, where this study took place. South Africa alone has 12 different languages with as many different cultures. There are some cultures in Africa where it is culturally permitted to have more than one wife. In most cultures where a man or a woman is allowed multiple partners, there is a procedure that has to be followed which involves the families of both parties. It seems that if the cultural procedures are followed, then culture could actually be used as a protective measure against the transmission of HIV. For example, HIV testing can be requested before the marriage ceremony. The King of Swaziland is reported to now have his new wives tested before the marriage ceremony. Other forms of multiple partners usually fall outside cultural practices and are similar to the kind of promiscuous behaviour that is rife in other societies. Multiple partners are a result of many factors including vast gender imbalances (as in the mining communities), values, economic factors, opportunities, and choice.

It is thus important to have a good understanding of cultural issues within all communities in order to avoid misrepresentation and discriminative behaviour toward groups in the community.

Basic infrastructure in the mining communities generally refers to services such as the transportation networks, access to school, sport and leisure facilities, and other basic services such as electricity and water. The major impact on the transmission of HIV infection in terms of infra-structure in the mining community is the lack of recreational facilities. Lack of recreational facilities has resulted in high and early dependence on illicit substances such as alcohol and drugs. This has its own impact on risky sexual behaviour. Campbell and Mzaidume (1999) found that the level of HIV infection differed amongst different networks of people: members of church and sports groups had lower levels of infection; people in savings clubs (informal savings societies in which members contribute regularly and receive payout on rotation) had higher levels as a result of generally having more sexual partners and a higher level of alcohol consumption.

\section{Addiction}

Alcohol remains the most commonly abused drug in South Africa, followed by dagga (cannabis) and the dagga and Mandrax (white pipe) combination (Parry 1998). South Africans consume well over five billion litres of alcoholic beverages per year. The figure could be nearer to six billion, depending on one's estimation of the amount of sorghum beer consumed (KWV 1997).

The overall prevalence of alcohol misuse in South Africa is likely to be as high as 30\% amongst certain groups and as low as about $5 \%$ in others, and can be dependent on factors such as age, gender, socio-economic status, and degree of urbanisation. Binge drinking amongst young people, especially males, is high (in excess of $25 \%$ in many communities). High levels of alcohol misuse have been reported amongst persons involved in certain occupations, for example, farming, mining, and amongst residents of disadvantaged communities where there is easy access to alcohol.

According to the community members and mine management being interviewed, alcohol abuse manifests itself in the form of increased violence during the weekends after payday, men not returning home or not turning up to work for a period of two to three days after being paid, and reports of rape around the beer-holes. Health problems related to alcohol problems, according to the communities, include the risk of rape, risk of transmission of HIV, and stress because of lack of money after a period of bingeing. There was limited knowledge of the impact of alcohol on other health issues such as damage to brain cells, liver, mental health, and other general illnesses. This lack of knowledge about the impact of alcohol on health was reflected by the lack of help-seeking behaviour related to alcohol problems. There are many factors contributing to this; some of these include not perceiving alcoholism as an illness therefore not seeking medical help, inadequate and overcrowded health care facilities which make it difficult to undertake appropriate assessment for an alcohol-related diagnosis, non-existent support groups, poor access to relevant therapeutic intervention in the area, and the shame and stigma associated with having an alcohol-related problem (Kleinman 1980). Littlewood and Lipsedge (2001) suggest that alcohol-related problems may not be recognised because they are mistakenly being identified as a reaction to problems relating to poor socio-economic conditions.

\section{Mental health}

With respect to understanding the meaning of the term mental health, it would be helpful to first take a look at the meaning of health in general. In the past, scientists defined health simply as 'an absence of disease or illness'. However, in 1948, when the World Health Organisation (WHO) was founded, the following definition of health was established: 'A complete state of physical, mental and social wellbeing and not merely the absence of disease or infirmity' (Tsai 2005). 
Mental health can thus be defined as:

... [a] state of emotional and psychological well-being in which an individual is able to use his or her cognitive and emotional capabilities, function in society and meet the ordinary demands of everyday life. It can also refer to a person's overall emotional and psychological condition. (Anon 2007)

However, mental health does not only refer to normal or 'average' human functioning, as it also includes different 'positive psychological aspects'. At the subjective level, there are valued subjective experiences: well-being, contentment, and satisfaction (in the past); hope and optimism (for the future); and flow and happiness (in the present) (Seligman \& Csikszentmihalyi 2000:5). At the individual level, there are positive individual traits: the capacity for love and vocation, courage, interpersonal skill, aesthetic sensibility, perseverance, forgiveness, originality, future-mindedness, spirituality, high talent, and wisdom. At the group level, there are aspects such as civic virtues and the institutions that move individuals toward better citizenship: responsibility, nurturing, altruism, civility, moderation, tolerance, and work ethic (Seligman \& Csikszentmihalyi 2000:5). Therefore, mental health means a balance between all aspects of life social, physical, spiritual and emotional - and it is far more than merely being the absence of mental illness (NEHB 2007).

In determining the state of mental health in the researched mining communities, one needs to focus not only on mental health problems or pathology, but also on what constitutes positive mental health. Looking at mental health through the scope of positive psychology, involves examining those conditions and processes that contribute to the optimal functioning of people, groups and institutions (Gable \& Haidt 2005:104). This is in line with definitions of mental health that describe not only the absence of disease, but the presence of different components of well-being. By utilising this approach to mental health, one is in a better position to make policy recommendations that can improve the mental health care in mining communities, beyond merely treating the illnesses caused by mental health.

The long-term impact of mining on the mental health of workers and communities becomes important when placed within the context of sustainable development. Coetzee (2001) argues that it is not sufficient to define development only in terms of concepts that describe progress, growth and reconstruction. Development should be based firmly on human well-being, the quality of human life and a large amount of human self-worth. This argument refers to the psychological well-being of persons, which is a very important component of mental health. Coetzee further believes that development should be focused on the need and aspirations of people, as it is defined by their own description. This argument seems to imply the importance of the concept subjective well-being, which is an essential element of overall mental health.

Stress is definitely the most prevalent mental health concern. This not only leads to other mental health problems, but is the root cause of other physical and social problems such as heart conditions, or mining accidents that occur due to poor concentration. People living and working in the mining environment experience stress for a variety of reasons that range from financial pressures, to coping with the expectations of the physical mine environment.

In conclusion of this section on mental health, the following are some of the stressors found in the mining environment, based on the voices from the ground in the communities (Cronjé \& Van Wyk 2010:259-268):

- production targets

- transformation

- financial pressures

- unnatural and unhealthy work environments

- migrant labour

- poor living conditions

- substance abuse

- shift work

- safety and physical health concerns

- mine culture.

In the next section, the natural factors related to health disasters will be discussed.

\section{Natural factors}

The environmental (natural) threats to health, that can of course reach disastrous proportions, can be summarised under the following:

- dust and other harmful particles in the air and water

- excessive noise from blasting and other mining operations

- overcrowded and unhygienic living conditions.

The most common illnesses and diseases associated with these environmental threats include: $\mathrm{TB}$, silicosis, airborne and water-associated illnesses (asthma, other chronic chest infections, sinusitis, eye problems, diarrhoea and cancer) and hearing problems.

\section{Tuberculosis}

The history and prevalence of tuberculosis (TB) in South Africa is synonymous with the country's industrialisation, primarily based on mining and former political and economical policies derived from the Apartheid era. In short, TB was first recognised as an important health hazard soon after gold mining started in the 1890s in South Africa. Black migrant miners, recruited from rural South Africa and surrounding neighbouring countries, were employed for short periods and often stayed home for extended periods between contracts. This coming and going of workers served as an agent for the spreading of TB within the communities and across the national boundaries. Furthermore, overcrowding, poor diets, and poor working conditions were at the time of this study identified as important factors contributing to TB amongst miners. Despite more knowledge and better treatment of the disease, the living and working conditions of mine workers have not changed significantly. Consequently, it is not surprising that current trends show that $\mathrm{TB}$ is on the increase in the mining sector. 
The rise in incidence of TB cases from 1991 coincides with the rise of HIV incidence in South Africa. Churchyard and Corbett (2001:153) show that the TB incidence amongst gold miners has paralleled the rising HIV prevalence in women attending state antenatal clinics.

From a global angle, 8.8 million new cases of TB around the world were reported by the World Health Organisation in 2010. A total of 5.7 million new and current TB cases were treated and 1.4 million people died of the disease, of which 350000 were HIV positive. The high level of HIV in South Africa thus exacerbates the incidence of TB as infected employees' immune systems are compromised, in turn increasing their risk of contracting TB.

\section{Airborne and water-associated illnesses}

Large-scale resource extraction projects can have a disastrous local and regional impact, including toxic contamination of ground- and surface water, air pollution, soil degradation, and loss of critical natural ecosystems and biodiversity. Runoff and leakage from tailing dams and existing wasterock dams pollute streams flowing out of the mining area, causing widespread damage downstream.

Industrial waste and pollutants are another mining-related environmental hazard. Solid waste produced by the separation of gold from ore is placed in dumps, and liquid waste is collected in pits, called slime dams. Both of these contain small amounts of active uranium. Radon gas emitted by the uranium poses a health threat when inhaled and can contribute to lung cancer and other ailments. Furthermore, the dust from mine dumps can contribute to respiratory diseases such as silicosis. In addition, the Medical Research Council concurred with this by stating that diarrhoea and airway infections, caused by poor environmental conditions, are amongst the top five causes of mortality in children (Pienaar 2004).

According to The Bench Marks Foundation (2012:v), mines on the Platinum Belt seem not to care about water impacts that cause health and livelihood problems, air quality issues that lead to respiratory problems, or the overall development of communities on whose land they operate. When it comes to environmental impacts, Anglo Platinum itself admits to exceeding permitted emission levels of sulphur dioxide $\left(\mathrm{SO}_{2}\right)$ and to harmful impacts on water resources in the area. The carbon dioxide $\left(\mathrm{CO}_{2}\right)$ and $\mathrm{SO}_{2}$ emissions associated with the increasing number of platinum smelters in mining areas give rise to acid rain, with a harmful impact on farming activities. Water sources are also being contaminated by both mining activities and the waste produced by informal settlements without access to waste removal and sewage systems. The locations of the informal settlements are closely linked to those of the platinum mines.

The presence of bilharzia in surface water is also a concern for The Bench Marks Foundation and is a direct consequence of informal settlements, a major cause of which are the housing policies of mining companies, and failure by Local Government to maintain and repair sewage and drainage systems. There are a variety of impacts of mining on water, for example excessive consumption, dropping of the groundwater table where open cast mining occurs, elevated levels of sulphides and nitrates in the water and the location of tailings dams and rock waste facilities that are too close to water sources.

High levels of dust are experienced, particularly around August and September in communities living in close proximity to tailings dams and dust roads used by mine vehicles. Elevated levels of dust contribute to ear, nose and throat complaints within communities (The Bench Marks Foundation 2012:139).

\section{Hearing problems}

Sound is regarded as noise if it has the potential to interfere with communication or damage people's hearing. Sources of noise and vibration in the mining environment are mainly from machinery, heavy transportation and blasting, especially in the cast areas. According to Burger et al. (2004:63), the South African Safety in Mines Research Advisory Committee (SIMRAC) identified noise-induced hearing loss (NIHL) as a major occupational health risk in the South African mining industry. Also, the number of compensation payments and the associated compensation for NIHL has increased substantially over the past few years. Another indicator of the severity of the problem is the data obtained from medical records submitted by South African mines to the chief inspector of mines for the period from 01 October 1999 to 30 September 2000. From this data, hearing loss ranks with TB as the largest occupational health risk in terms of numbers of workers affected. The World Health Organisation suggests that noise can affect human health and well-being in a number of ways including annoyance reaction, increased number of headaches, greater susceptibility to minor accidents, loss of sleep, increased mental hospital admission rates and hearing loss.

Some of the community settlements in the study are located less than 500 metres away from the mine operations, and they, therefore, feel the brunt of the noise and vibrations from the mine operations. With regard to the mine hospitals and clinics in this study, only permanent employees of the mine have access to those services. Consequently, dependents of mine employees have to rely on either government clinics or the private sector. Most of these people obviously make use of government facilities, which are not as adequately equipped as the mine facilities. The implication of this is that government clinics are being overburdened by additional patients that are not accounted for by government structures.

Despite structured noise control levels and a compensation system at work, there is generally still very little awareness or consideration for the surrounding communities.

In order to address the third objective of this study, the issue of health and community involvement will now be discussed. 


\section{Health issues and community involvement: Tradition versus modernity}

Traditionally, mine workers ('settlers') brought in by mining companies to work for the mine range in composition from managers and skilled workers such as engineers, geologists and administrative staff, to cheap migrant labourers. The 'settlers' found themselves accommodated in mining towns by the mining corporations in towns such as Kleinzee and Welkom (South Africa), Ndola, Kitwe and Kabwe (Zambia), and Kolwezi and Likasi (DRC), where the corporation provided not only housing, but also sport and recreation, arts and culture and health and municipal services. Cheap black African migrant labour was housed in 'compounds' or in 'hostels,' whilst the invariably white managerial, skilled and administrative staff were housed in the mining town in houses and flats ranked hierarchically according to position, income and status. The advantages and disadvantages of these mining towns were admirably captured by Peter Carstens in his seminal book on Kleinzee (Carstens 2001).

The inhabitants of these mining towns, whilst being subject to the paternalistic authority of the corporation, were exposed to the direct health and safety risks of the mining operation, but also had access to extensive medical support from the medical services provided by the mine. In many cases this meant access to both doctors and the mine hospital. The employees were also trained in first aid, disaster management drills, and mine health and safety (Johnson 1987:85-91).

Since 1994 the phenomenon of the Company Town has waned dramatically as the new focus of mining corporations on their core business of 'mining' has led to the privatisation of mining towns and housing stock. The Mining Charter in South Africa and changes in legislation in the rest of Southern Africa have also seen the closure of mine 'compounds' and hostels for 'migrant' workers, with definite impacts on both the health and safety of mine workers, their dependents and that of near-mine communities.

After 1994, the South African mining industry, following global trends, began to 'right size', and cut down on supply side costs, rapidly moving away from the 'miniature welfare state' model so as to maximise profits for shareholders. Most began to introduce medical aid with deductions from both the employer and the employee as required by new labour legislation. The Mining Charter required a scaling back of mine hostels and migrant labour, and the introduction of family housing. Many mines began a process of converting mine hostels into family accommodation.

For more skilled categories of labour, the mines worked out finance packages for mine workers to buy houses, and for unskilled mine workers preferring not to stay in the hostels, the mining companies introduced the 'living-out allowance', which ranged from R800 to R1000 per month. The livingout allowance served the dual function of reducing the men living in hostels as well as hiding the extent of the mine's dependency on migrant labour. Many mines - also companies in the study area - now claim to recruit within a $40 \mathrm{~km}$ radius of their operations. The research, however, reveals that thousands of mine workers on the livingout allowance are now living either in shacks in 'informal settlements' or in backyard shacks or rooms in nearby villages or townships. These backyard dwellings in the already limited space around Reconstruction and Development Plan (RDP) housing has had a crippling effect on services and infrastructure in the Bojanala District: in particular, sewage systems are constantly breaking down under the pressure of overutilisation, and illegal electricity connections are overloading the electricity supply system. This has resulted in health disasters and near-disaster situations. Examples are the outbreak of cholera in Klerksdorp's Kanana Township (Kaunda 2004) and the appearance of bilharzia in the river systems around Rustenburg (SAPA 2003); these examples show that there needs to be far greater involvement of local government and local communities in mine planning and management. The tragic events that happened in Marikana can, of course, be indirectly linked to the abovementioned issue as well.

This change in policy from 'miniature welfarism' to ultra supply-side economics in mining happened at the unfortunate moment when HIV hit the mining industry, and has had the effect of petrol and a burning match on a haystack as far as near-mine communities are concerned with regard to HIV. It is often argued that the old social welfare model created an unnecessary dependency by the mine worker on the mining company. However, the new model, which sees deductions of medical aid, pension and rent from the already very low wages of mine workers, has resulted in an externalisation of costs from the mine to local and district governments who are already struggling to provide services to communities demanding their constitutional and legal rights to such services.

It is critically important that mines, Local Government and communities collaborate to avert health disasters and to plan to cope jointly with these disasters when they do happen. This is true for both slowly unfolding disasters such as respiratory and other health problems emanating from airborne and water pollution, and for sudden disasters such as the explosion of a diesel supply truck in the middle of a community, the spilling of radioactive or toxic substances as a result of a road accident, or the failure of a tailings dam. With 'slow' health disasters, for example HIV, TB, mental health problems, and others, urban planning, environmental impact monitoring and sound management at different governance levels (companies and government) play very important roles.

In the important engagement process, concepts such as stakeholder engagement and dialogue, stakeholder's perceptions and Social Responsibility strongly come to the fore. Such a collaborative approach between mining companies, Local Government and communities, would 
require regular meetings in the form, possibly, of a joint disaster management committee involving the mine disaster management team, the Local Government disaster management team and community structures, such as the monitors that the Bench Marks Foundation has been training over the last three years, and which now involves 27 near-mine communities. The important shift to be made is to realise that health issues can result in even more severe disasters than disasters caused by natural and work-related factors. Apart from the role of mine management and Local Government's involvement, communities - through community monitors - must become the eyes and ears of the area, especially in alarming and warning the wider society about the increasing ramification of health disasters. Community monitors can provide basic observations and reports on health threats such as the impact of dust on the community, visit surface water sources to do basic water quality checks, perform surveys of derelict and/or substandard housing, and bring general health complaints to the attention of both the mining company and Local Government. Underlying all this is, of course, the critical question of literacy and training in communities.

On the issue of community engagement and involvement, the recent events at Marikana (August 2012) must serve as a timely warning against, amongst other things, poor community engagement and involvement. Workers with grievances obviously live in adjacent communities, and the combination of work-related problems, utterly poor living conditions, service delivery that is non-existent, as well as labour union politics, are all very dangerous ingredients in an already over-heated 'melting pot'. The important point to make is that proper consultation and engagement with communities as well as the constant application of the principle of free prior, and informed consent (FPIC) regarding different issues (labour, housing, potential environmental and health hazards, etc.) can definitely play a preventive role with regard to disasters of all kinds.

All mining companies do have zero harm, accident and disaster mitigation strategies and policies. However, these strategies are narrowly workplace-focused and do not take into consideration external factors that could compromise workplace health and safety. Consequently, and in line with the last objective of the study, some recommendations in order to prevent health-related disasters in the mining sector will be presented.

\section{Recommendations}

Researchers at the Bench Marks Foundation and authors of this article are of the opinion that many 'workplace and health disasters' could be avoided if:

- mines had higher literacy rates

- safety training took place at the rock-face rather than after shifts

- workers were living in better conditions

- more locals rather than migrants were employed

- subcontracting could be stopped
- safety bonuses exceeded productivity bonuses

- managers could be held criminally liable for mine disasters and accidents.

\section{Literacy rates}

Despite spending millions on Adult Basic Education Training $(\mathrm{ABET})$, it would seem as if mining companies are not making any impact on literacy levels at their operations.

The reasons for this inability to deal with poor levels of literacy are obvious:

- The reliance on subcontracted labour. One cannot teach temporary workers to read and write - they are employed only for short periods of time and therefore any funds spend on their education is wasted.

- The reliance on migrant labour. Migrant workers traditionally come from labour-sending areas in the country with the worst educational services and infrastructure in the country such as the Eastern Cape and former Bantustan areas. Migrant labour is also highly mobile and transient, again causing education spending on such workers to be a waste of money. Other migrant workers come from countries such as Mozambique that have recently experienced a disruptive civil war, and Lesotho where there is a lack of education infrastructure in remote rural areas.

Most mines are located close to urban areas with high levels of youth unemployment, yet with high levels of literacy and education. Thus in the villages and townships of Rustenburg there are thousands of matriculants who are keen to work in the mines yet are told that they cannot be employed because they lack 'maths and science', or they lack 'mining experience'. This disingenuous response by mining companies is entirely unacceptable, especially in some cases where the corporation reports literacy levels as low as 57\% (IMPLATS 2012). In a study on mining in Rustenburg done by The Bench Marks Foundation in 2007, the literacy level was exactly the same as in 2012 despite the company's spending millions of Rands on its ABET programme (The Bench Marks Foundation 2007:33-39). Not surprisingly, many mines have experienced disruptions over the last year as a result of unemployed youth protesting violently against the mines' employment policies and practices.

Workers who are able to read and understand health and safety signage would be less prone to disasters, including health disasters.

\section{Timing of training}

Workers and shop stewards interviewed complain that health, safety and disaster management training mostly takes place in classroom situations after or between shifts. In other words, workers are expected to give up their free time to do workplace health and safety training. The Bench Marks Foundation has found through their SADC research that workers are often hungry and exhausted after shifts and lack the concentration required to make this training effective. 


\section{Living conditions}

Many workers find themselves living in shacks in squatter camps or in backyard dwellings in townships and villages. Very often, they do not have access to clean water or electricity in these circumstances. There are also no sport and recreation facilities available apart from sex workers and shebeens. Workers burn coal, wood, paraffin and, at times, tyres and plastics, for fuel to allow them to cook and prepare food.

The workers are exposed to excessive drinking, not eating properly and, being single, often have multiple partners in that they use the services of sex workers, thereby exposing themselves to STIs and HIV. These living conditions also have an impact on their concentration at the rock-face underground and are therefore serious factors in workplace health and safety. Lastly, it is inevitable that the poor living conditions will contribute to mental health problems.

\section{Subcontracting and local employment}

It has already been shown that the literacy problem on mines could be overcome if companies were to employ literate unemployed youth from local communities instead of large numbers of illiterate migrants. It was also shown through the research that workers - mostly contract workers - living in back rooms and shacks due to improper housing and living conditions pose a health and safety risk, not only to the mining operation where a lack of concentration could lead to a mine disaster, but also to their communities in terms of STIs, HIV, TB, and substance and alcohol abuse. The Bench Marks Foundation has also found increased levels of violence and crime in areas where there are large concentrations of migrant workers. Furthermore, there is also a strong correlation between outbreaks of xenophobia and areas where there are high numbers of foreign migrant workers (The Bench Marks Foundation 2007:23).

In the last instance, subcontracting poses a major risk to mine safety in that the mining company employing the subcontractor has no control over the training and skills of the workers employed by the subcontractor. Labour unions such as the National Union of Mineworkers (NUM) have regularly complained about the possibility that subcontracted workers compromise mine safety.

\section{Safety bonuses versus productivity bonuses}

Shop stewards (Etheridge 2010) and safety officers (Anon 2012) have noted a link between productivity bonuses and mine fatalities, whilst the Minister of Mineral Resources has suggested a '... link between the body count and profits' (Roelf 2011). The Bench Marks Foundation established the link between bonuses as long ago as 2007. Simply put, safety is compromised as workers chase bonuses. The number of accidents increase as production is accelerated to meet increasing prices, and there are huge bonuses at stake on the days just before long weekends and the Christmas holidays as workers attempt to increase income to take home for the holidays (The Bench Marks Foundation 2007:56). As long as productivity bonuses are compromising safety standards, potential disasters over a wide frontier will loom over the industry.

\section{Conclusion}

This paper focused on the social and natural factors involved in the creation of health disasters. The social factors include poverty, unemployment, poor housing and infrastructure, prostitution and a high influx of unaccompanied migrant labour. Major health issues in this regard, which were highlighted, are the extraordinarily high incidence of HIV and STIs, addiction and mental illness.

The environmental (natural) threats to health that were discussed in the study were dust and other harmful particles in the air and water, excessive noise from blasting and other mining operations, and overcrowded and unhygienic living conditions. The most common illnesses and diseases associated with these environmental threats include TB, silicosis, airborne and water-associated illnesses (such as asthma, other chronic chest infections, sinusitis, eye problems, diarrhoea and cancer) and hearing problems.

The research also has far reaching implications toward, and makes a strong case for, Social Responsibility (SR). The mining companies must accept their responsibility with regard to these health disasters as well as the importance of community involvement in the management process. Proper corporate accountability is necessary to ensure that there is an adequate balance between economic development and the well-being of people and the environment. Despite companies' CSR and sustainability policies, there is little evidence that companies are addressing their long-term responsibilities, especially in terms of health issues (Stephens \& Ahern 2001:46). On the other hand, the gap between policy and legislation of government departments and practice is hugely problematic, and government on all three levels must be serious in their efforts to internalise the implementation and monitoring of disaster and other SR-related legislation in order to ensure a safer environment and to enhance sustainability.

Another objective of the paper was to show that communities need to be 'fenced in' in terms of disaster management instead of being excluded. This should be done by using structures that have arisen within communities as a result of their concerns about the impact of mining on their lives. A holistic approach where there is information-sharing between different 'angles' and parties should be the order of the day. Excluding the communities regarding this very important issue could have costly and tragic consequences. The Constitution of South Africa envisages a future South Africa that is a caring society, which implies that we should cooperate in minimising the risks to workers and communities of all potential disasters. Specific recommendations to mining companies to reduce health and safety disasters were made to conclude the article. 


\section{Acknowledgments Competing interests}

The authors declare that they have no financial or personal relationship(s) which may have inappropriately influenced them in writing this paper.

\section{Authors' contributions}

F.C. (North-West University) was the project leader, researcher and wrote the manuscript, S.R. (North-West University) was a researcher and wrote the manuscript, D.V.W. (North-West University) was a researcher and wrote the manuscript.

\section{References}

Anon., 2007, 'Mental health', viewed 15 July 2007, from http://www.answers.com/ topic/mental-health

Anon., 2012, 'More than 100 recorded deaths in South African mines last year', Financial Mail, 19 January, viewed 24 July 2012, from http://www.miningsafety. co.za/newscontent/317/More-than-100-recorded-deaths-in-South-Africanmines-last-year

Bekker, S.B. \& Swart, K., 2003, 'The relationship between migration and the HIV/AIDS pandemic: a preliminary South African analysis', in R. Cohen (ed.), Migration and health in Southern Africa, pp. 63-68, Van Schaik, Cape Town.

Brummer, D., 2002, Labor migration and HIV/AIDS in Southern Africa, International Organization for Migration Regional Office for Southern Africa.

Burger, N.D.L, Von Wielligh, A.J., De Wet, P.R., Otterman, R.W. \& Steyn, J.L., 2004 'Design and development of a low noise rockdrill', Journal of the South African Institute of Mining and Metallurgy 104(7), 403-410.

Campbell, C. \& Mzaidume, Y., 1999, 'Social capital and grassroots participation in community health projects', paper presented at the First International Conference on Critical and Qualitative Approaches to Health Psychology, St Johns, Canada.

Carstens, P., 2001, In the company of diamonds: De Beers, Kleinzee and the control of a town, Ohio University Press, Athens.

Churchyard, G.J. \& Corbett, E.L., 2001, 'Tuberculosis and associated diseases', in R. Guild, R.I. Ehrlich, J.R. Johnson \& M.H. Ross (eds.), Handbook of occupational health practice in the South African mining industry, pp. 153-192, SIMRAC, Johannesburg.

Coetzee, J.K., 2001, 'A micro-foundation for development thinking', in J.K. Coetzee, J. Graaff, F. Hendricks \& G. Wood (eds.), Development: theory, policy and practice, p. 119, Oxford University Press, Cape Town.

Colvin, M. \& Sharp, B., 2001, 'Communicable diseases and poverty in Southern Africa', paper presented at the Southern African Regional Poverty Network symposium, Pretoria, South Africa, April 26.

Cronjé, J.F. \& Chenga, C.S., 2007, 'Health issues in a mining community in South Africa', in T. Falola \& M. Heaton (eds.), HIV/AIDS, illness and African well-being pp. 210-242, Rochester Press, Austin.

Cronjé, J.F. \& Van Wyk, L.J., 2010, 'Mental health concerns in the South African mining sector: What about corporate social responsibility?', in L. Heinecken \& H. Prozesky (eds.), Society in focus - change, challenge and resistance: Reflections from South Africa and beyond, pp. 251-270, Cambridge Scholars Publishing, Newcastle upon Tyne.

Etheridge, J., 2010, 'NUM raises mine safety debate', Mail and Guardian, 13 October, viewed 24 July 2012, from http://mg.co.za/article/2010-10-13-num-takes-aim-atsa-mine-safety

Gable, S.I. \& Haidt, J., 2005, 'What (and why) is positive psychology?', Review of General Psychology 9(2), 103-110. http://dx.doi.org/10.1037/1089-2680.9.2.103

Hamann, R. \& Kapelus, P., 2004, 'Corporate social responsibility in mining in Southern Africa: Fair accountability or just greenwash?', Society for International Development 47(3), 85-92.
IMPLATS (Impala Platinum), 2012, 'Sustainable development report', viewed 23 July 2012, from http://www.financialresults.co.za/2011/implats_sr2011/hc-people. php

Johnson, P., 1987, Gold fields, a centenary portrait, Weidenfeld and Nicholson, London.

Kaunda, P., 2004, 'NW Battles Cholera', Daily Sun, 13 April, viewed 24 July 2012, from http://152.111.1.87/argief/berigte/dailysun/2004/04/13/DS/32/01.htm

Kleinman, A., 1980, Patients and their healers in the context of culture, University of California Press, Berkeley.

Krefting, L., 1991, 'Rigor in qualitative research: the assessment of trustworthiness', The American Journal of Occupational Therapy 45(3), 214-222. http://dx.doi. org/10.5014/ajot.45.3.214

KWV, 1997, SA wine industry statistics, KWV, Paarl.

Littlewood, R. \& Lipsedge, M., 2001, Aliens and alienists: ethnic minorities and psychiatry, 3rd edn., Routledge, London.

Meeran, R., 2003, Corporate accountability: Why?, Leigh Day and Co, London.

NEHB (North Eastern Health Board), 2007, 'Mental Health Definition', viewed 14 June 2012, from http://www.nehb.ie/youthhealthne/mental\%20health\%20definition. htm

Palmquist, M., Busch, C., De Maret, P.S., Flynn, T., Kellum, R., Meyers, B., Saunders, M $\&$ White, R., 2005, 'Content analysis', viewed 30 June 2007, from http://writing. colostate.edu/guides/pdfs/guide61.pdf

Parry, C.D.H., 1998, 'Substance abuse in South Africa: country report focusing on young persons', Mental health and substance abuse, Medical Research Council, South Africa, viewed 30 June 2007, from http://www.sahealthinfo.org/admodule/ countryreport.pdf

Patton, M.Q., 2002, Qualitative research and evaluation methods, 3rd edn., Sage Publications, Thousand Oaks.

Pienaar, A., 2004, 'Omgewingstoestande laat talle kinders sterf', Beeld, 23 November.

Roelf, W., 2011, 'Mine "carnage" worries Susan Shabangu', Mail and Guardian, 18 July, viewed 24 July 2012, from http://mg.co.za/article/2011-08-18-mine-carnageworries-susan-shabangu

SAPA, 2003, 'Bilharzia pupils doing well', viewed 24 July 2012, from http://www. news24.com/SouthAfrica/News/Bilharzia-pupils-doing-well-20030905

Seligman, M.E.P. \& Csikszentmihalyi, M., 2000, 'Positive psychology: an introduction', American Psychologist 55(1), 5-14. http://dx.doi.org/10.1037/0003-066X.55.1.5

South African Government, 1996, Constitution of the Republic of South Africa 1996, Government Printers, Pretoria.

South African Government, 1996, Mine Health and Safety Act 29 of 1996, Government Printers, Pretoria.

South African Government, 2002, Disaster Management Act 57 of 2002, Government Printers, Pretoria.

South African Government, 2002, Mineral and Petroleum Resources Development Act 28 of 2002, Government Printers, Pretoria.

South African Government, 2005, National Disaster Management Framework, Government Printers, Pretoria.

South African Government, 2010, Mining Charter of South Africa, Government Printers, Pretoria.

Stephens, C. \& Ahern, M., 2001, Worker and community health impact relating to mining operations internationally: a rapid review of the literature, London School of Hygiene and Tropical Medicine, London.

The Bench Marks Foundation, 2007, The Policy Gap: a review of the corporate social responsibility programme of the platinum mining industry in the North West province, The Bench Marks Foundation, Johannesburg.

The Bench Marks Foundation, 2012, Policy Gap 6: Communities in the platinum minefields. A review of platinum mining in the Bojanala district of the North West province: A participatory action research (PAR) approach, The Bench Marks Foundation, Johannesburg.

Tsai, G., 2005, 'What is mental health?', viewed 18 June 2007, from http://health. howstuffworks.com/mental-health/mental-disorders/what-is-mental-health.htm

Warhurst, A., 1998, 'Corporate social responsibility and the mining industry', paper presented at Euromines, Brussels, 04 June.

Webb, D., 1997, HIV and AIDS in Africa, Pluto Press, London.

Whiteside, A., 2001, 'AIDS and poverty: the links', AIDS Analysis Africa 12(2), 1-5.

World Health Organisation, 2010, 'Global Health Observatory: Tuberculosis', viewed 22 August 2012, from http://www.who.int/gho/tb/en/index.html 